\title{
Accuracy of diffusion-weighted magnetic resonance imaging in evaluation of muscle invasion and histologic grading of the urinary bladder carcinoma
}

\author{
Sahar Mahmoud Abd elsalam ${ }^{1 *}$ and Ahmed Mahmoud Abdelbary ${ }^{2}$
}

\begin{abstract}
Background: Carcinoma of the urinary bladder is a common malignant tumor of the urinary tract in both men and women. Proper management of the urinary bladder cancer depends on the stage of the lesions. The aim of this prospective study was to determine the accuracy of diffusion-weighted images in early detection of muscle invasion, local tumor staging of urinary bladder carcinoma, and to measure the correlation between apparent diffusion coefficient (ADC) and histologic grade. Sixty patients with urinary bladder mass lesions underwent transurethral cystoscopy and biopsy after MR imaging. Radical cystectomy was done for lesions infiltrating muscularis propria. Different MR image sets (T2WIs, DWls images) were interpreted; ADC values of tumors were calculated.

Results: Kappa agreement was better in DWI than T2WI (Kappa was 0.756 and 0.484) and the overall agreement was (83.6\% and 63.6\%) among both respectively. Accuracy of DWI in diagnosis of tumor stages were $80 \%, 43 \%, 96 \%$, and 100\% while in T2WI were 55\%, 43\%, 74\%, and 80\% for T1, T2, T3, and T4 stages respectively. ANOVA test showed statistically significant difference between mean ADC values of different tumor grades.

Conclusion: DWI showed higher accuracy than T2WI in detection of the degree of muscle invasion of the urinary bladder carcinoma, so it can be added to the routine protocol of MRI examination especially in patients with renal impairment. ADC value can predict the histological grade of the tumor.
\end{abstract}

Keywords: Urinary bladder, Carcinoma, DW-MRI, Muscle invasion

\section{Background}

Carcinoma of the urinary bladder is a common malignant tumor of the urinary tract in both men and women [1]. It is the fourth most common cancer in males and the tenth most common cancer in females [2]. Most cases of urinary bladder cancer occur in males. The highest incidence rates are found in Europe, North America, and Northern Africa [3].

Smoking and occupational exposures are considered the major risk factors of urinary bladder carcinoma [4]. Tobacco-related bladder cancers are commonly transitional cell carcinoma $[5,6]$.

\footnotetext{
*Correspondence: shahdsahar@yahoo.com; saharmahmoud575@gmail.com

${ }^{1}$ Faculty of Medicine, Beni-suef University, Beni-suef, Egypt

Full list of author information is available at the end of the article
}

Proper management of the urinary bladder cancer depends on the stage of the lesions. Cases with muscle invasive bladder carcinoma (MIBCs) are treated with neoadjuvant chemotherapy, radical cystectomy, and lymphadenectomy while in non-muscle invasive bladder carcinoma (NMIBCs) transurethral resection + chemo/immunotherapy are to be considered [7]. TUR biopsy is considered invasive technique which may be risky particularly in patients with bleeding disorders [8].

MRI is the most promising imaging modality for diagnosis and local staging of urinary bladder cancer. MRI has many advantages including multiplanar imaging, better detection of tumors, better soft tissue characterization, and superiority in evaluation of pelvic organs invasion [9]. 
Diffusion-weighted imaging (DWI) is considered a diagnostic technique in evaluation of neoplastic lesions. It can distinguish pathologic lesions with high tissue contrast against generally suppressed background signal. Diffusion of water molecules is inversely proportional to the tissue cellularity. The high cellularity and intact cell membrane of malignant lesions show restricted diffusion [10, 11]. The apparent diffusion coefficient (ADC) value has been reported as quantitative measure of the degree of malignancy of the lesions. Decreased ADC values were reported with malignant lesions which have a larger cell diameter and more cellularity than normal tissue [12].

Diffusion-weighted images provided useful information for evaluating the local $\mathrm{T}$ stage of the urinary bladder cancer, particularly in differentiating $\mathrm{T} 1$ stage or lower tumors from T2 stage and higher tumor stages [13].

In this regard, the aim of our study was to determine the accuracy of diffusion-weighted images in early detection of muscle invasion, local tumor staging of urinary bladder carcinoma, and to measure the correlation between apparent diffusion coefficient (ADC) and histologic grade.

\section{Methods}

\section{Patients population}

The study was done between March 2017 and April 2018. Sixty patients presenting with gross hematuria and urinary bladder mass lesions detected on US and/or CT examinations were examined by pelvic MRI followed by transurethral cystoscopy resection and biopsy. MRI examination was done before transurethral cystoscopy resection and biopsy to avoid susceptibility artifacts from air due to cystoscopy that may distort diffusion-weighted imaging. The pathological stages were classified as the following: non-muscle invasive bladder carcinoma (NMIBCs) lesions $(<\mathrm{T} 1)$ and muscle invasive bladder carcinoma (MIBCs) (> T2). Cases with invasive bladder cancer (MIBCs) were managed by radical cystectomy and histopathological analysis of the specimens. Exclusion criteria included are the following: benign urinary bladder lesions and general contraindications to MR imaging (pacemaker, metallic prostheses,...etc.). Cases with renal impairment were not excluded from the study as we do not use contrast media. All cases of the study were examined clinically and managed by consultant urologist (20 years' experience).

The study was conducted in full accordance with the guidelines for Good Clinical Practice and the Declaration of Helsinki. Our study was approved by the ethical committee of our institution. Data for patients were collected only after obtaining their informed consents.

\section{MR imaging technique}

Patients were instructed to drink about $500-1000 \mathrm{ml}$ of water $1 \mathrm{~h}$ before the MR imaging examination and came for examination with a full urinary bladder. Fullness of the urinary bladder was checked during MRI examination on localizer images. In patients with a urethral catheter, 250$400 \mathrm{ml}$ of sterile saline was used to distend the bladder. We asked the patients to use antispasmodic agent before the examination to reduce bowel peristalsis. MR imaging was performed by using (Siemens aera 1.5 T Syngo MR E11 Germany and GE medical system SIGNA HDXT 16 channel USA $1.5 \mathrm{~T}$ ) devices. Initially, turbo spin-echo T2weighted images (T2WIs) in axial, coronal, and sagittal planes were obtained with the following parameters: repetition time $(\mathrm{TR})=2250-3500 \mathrm{~ms}$, echo time $(\mathrm{TE})=90$ $100 \mathrm{~ms}$, bandwidth $=20-83 \mathrm{kHz}$, matrix $256 \times 256$, slice thickness of 3-4 mm, intersection gap $=1-2 \mathrm{~mm}$, and field of view $=20 \mathrm{~cm}$. Then, with the patient free breathing, DW images were obtained in the axial plane by using a body coil and a mono-directional gradient multisection fast spin-echo echoplanar sequence using the following: repetition time $(\mathrm{TR})=3500-4500 \mathrm{~ms}$, echo time $(\mathrm{TE})=$ $60-70 \mathrm{~ms}$, bandwidth $=142 \mathrm{kHz}$, matrix $256 \times 256$, section thickness $=3-4 \mathrm{~mm}$, intersection gap of $1-2 \mathrm{~mm}$, and field of view $=36 \mathrm{~cm}$. Signals were acquired with $b$ values of 500 and $1000 \mathrm{~s} / \mathrm{mm}^{2}$. We used two $b$ values (500 and $1000 \mathrm{~s} / \mathrm{mm}^{2}$ ) as accurate quantitative analysis of diffusion-weighted imaging (ADC maps) that can be performed only if at least two $b$ values were used. Both $b$ values $\left(500\right.$ and $1000 \mathrm{~s} / \mathrm{mm}^{2}$ ) were used for better assessment of the region of persistent restricted diffusion. Thirty to 55 sections were obtained in $60-120 \mathrm{~s}$ to cover the pelvis including the whole urinary bladder, adjacent pelvic organs, pelvic side walls, and proximal part of the urethra. In some cases, DW images were obtained in the sagittal and/or coronal plane to be perpendicular to the base of the tumors. To gain better signal-to-noise ratios, a larger field of view was used for DWI than for T2WI.

\section{Image analysis}

All MR image sets were analyzed by radiologist with 10 years' experience reading body MR images who was blind to the results of cystoscopy and histopathological findings. Qualitative and quantitative analyses of the urinary bladder mass lesions were done. Qualitative analysis included the site, size, shape, and extension of the lesions. Quantitative analysis was done by measuring the $\mathrm{ADC}$ values of the urinary bladder mass lesions. Interpretation of T2-weighted images alone, DW images alone, and T2-weighted plus DW images were done.

\section{Tumor staging}

Tumor staging on DWI and T2WI were done as shown in (Tables 1 and 2). The normal bladder wall was seen as a low signal intensity (SI) line on T2-weighted images. The bladder wall was intact (stage $\mathrm{T} 1$ or lower) when the low SI line was present. The bladder wall was invaded by the tumor (stage T2 or higher) when the low SI line was disrupted focally in the region underlying the 
Table 1 T staging on T2WI [10, 11]

\begin{tabular}{ll}
\hline T stage & Description \\
\hline T1 or & Preserved low signal line of the normal bladder musculosa \\
$<$ & \\
T2 & $\begin{array}{l}\text { Disrupted low SI line focally in the region underlying the } \\
\text { tumor }\end{array}$ \\
T3 & $\begin{array}{l}\text { Lesions extending beyond the low signal line into the } \\
\text { perivesical fat }\end{array}$ \\
T4 & Lesions extending to the adjacent organs
\end{tabular}

tumor. On DW images, bladder cancer had been reported to show high SI (Fig. 1).

\section{ADC maps}

ADC maps were generated automatically by the MRI device. The urinary bladder lesions showed hypointense signal. We drew the region of interest (ROI) within the mass lesion at the most hypointense area. The ADC values were measured to estimate the degree of diffusion.

\section{Histopathologic analysis}

Transurethral cystoscopy resection and biopsy were done for all cases after MRI examination by consultant urologist. The acquired specimens were including the muscularis propria. The histopathological results obtained from the transurethral cystoscopy resection and radical cystectomy were used as the standard reference of the study results. Pathological data included are the following: tumor type whether transitional or squamous cell carcinoma, the local $\mathrm{T}$ stage of the urinary bladder cancer, and the histologic grade. The $\mathrm{T}$ stage of the tumor was classified into four stages (Table 3). Histologic grading was evaluated where tumors were classified into three grades: G1, the least degree of anaplasia; G2, intermediate degree of anaplasia; and G3, severe anaplasia.

\section{Statistical analysis}

Analysis of data was performed using SPSS v. 22 (Statistical Package for Social science) for Windows. Description of quantitative variables was in the form of mean, standard deviation (SD), minimum, and maximum. Oneway ANOVA test was used to detect the difference of scale variables between more two groups and post hoc

Table 2 T staging on DWI [13]

\begin{tabular}{ll}
\hline $\begin{array}{l}\text { T } \\
\text { stage }\end{array}$ & Description \\
\hline T1 or & $\begin{array}{l}\text { A thin, flat, high Sl area or high SI mass with a low SI } \\
<\end{array}$ \\
submucosal stalk (stalk sign) or a thickened submucosa \\
T2 & $\begin{array}{l}\text { A high SI tumor without a submucosal stalk and with a smooth } \\
\text { margin }\end{array}$ \\
T3 & $\begin{array}{l}\text { Lesion extension into the perivesical fat with an irregular } \\
\text { margin }\end{array}$ \\
T4 & Lesions extension into adjacent organs \\
\hline
\end{tabular}

test; Tukey HSD was used to detect the statistical difference between mean ADC values among different grades of tumor. Kappa agreement was used to compare between the results of diffusion-weighted imaging, T2WI, and the pathological findings, considering the pathological data as the gold standard in our study. Receiver operating characteristic (ROC) curve was used to predict the tumor invasiveness by using ADC values. The significance of the results was assessed in the form of $P$ value that was differentiated into the following: nonsignificant when $P$ value $>0.05$, significant when $P$ value $\leq 0.05$, and highly significant when $P$ value $\leq 0.01$.

\section{Results}

This descriptive study included 60 patients with single urinary bladder mass lesion in each patient. Five cases were excluded from statistical analysis as the bladder masses were proved to be benign by cystoscopy and biopsy while the aim of our study was to detect muscle invasion and histologic grade in urinary bladder carcinoma. The cases were complaining of gross hematuria. Their age ranged from 50 to 78 years with mean (62.44) years \pm standard deviation (7.63) years. The study included 35 males (63.6\%) and 20 females (36.4\%).

All patients underwent transurethral cystoscopy resection and biopsy after MRI examination. Thirty-five cases with lesions invading muscularis propria were managed by radical cystectomy and pathological evaluation of the specimens.

The $\mathrm{T}$ staging of the urinary bladder tumors according to T2WI findings revealed $11(20 \%)$ patients with T1, 11 (20\%) patients T2, 24 (43.6\%) T3, and 9 (16.4\%) T4, considering $\mathrm{T} 1$ as non-muscle invasive (NMIBCs) while T2, $\mathrm{T} 3$, and $\mathrm{T} 4$ as variable degrees of muscle invasive lesions (MIBCs).

Diffusion-weighted imaging revealed that 16 (29.1\%), 7 (12.7), $26(47.3 \%)$, and $6(10.9 \%)$ patients had T1, T2, $\mathrm{T} 3$, and T4 stages, respectively. The ADC values were estimated and their mean \pm SD were $1.27 \times 10^{-3} \pm 0.34$ $\times 10^{-3} \mathrm{~mm}^{2} / \mathrm{s}$, ranged (from $0.77 \times 10^{-3}$ to $1.87 \times 10^{-3}$ $\mathrm{mm}^{2} / \mathrm{s}$ ) with median $0.12 \times 10^{-3} \mathrm{~mm}^{2} / \mathrm{s}$.

Histopathological results after transurethral cystoscopy resection and radical cystectomy illustrated that 20 (36.4\%), 7 (12.7), 23 (49.1\%), and 5 (9.1\%) patients had T1, T2, T3, and T4 stage, respectively. Also, the histopathological examination demonstrated that $12(21.8 \%)$ cases were of grade 1 (low grade tumor), 14 (25.5\%) were of grade 2 (intermediate grade tumor), and 29 $(52.7 \%)$ were of grade 3 (high grade malignancy). The transitional cell carcinoma was the commonest cell type in this study $49(89.1 \%)$ but squamous cell carcinoma was detected in only $6(9.1 \%)$ cases.

The results of histopathological examination were compared to the results of T2WIs and diffusion- 


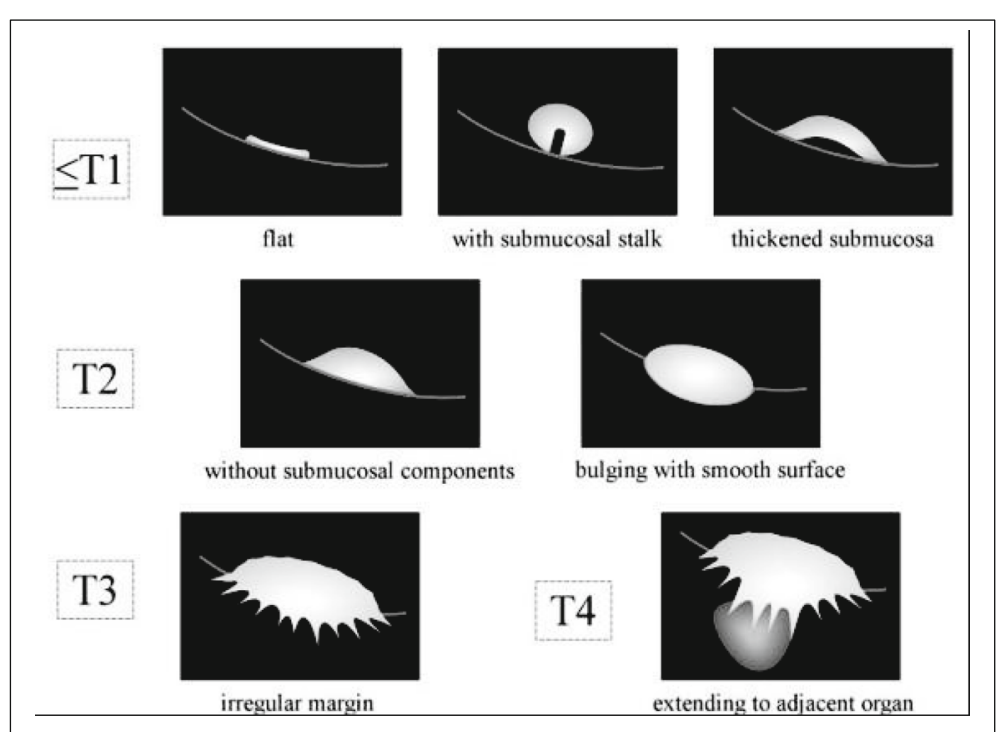

Fig. 1 Diagram shows diagnostic criteria for using DW imaging for staging bladder cancer. Cancer component, muscle layer, and submucosa show high, intermediate, and low SI, respectively. Submucosal stalk or thickened submucosa indicates T1 or lower stage; smooth tumor margin without submucosal components, T2; irregular margin toward the perivesical fat tissue, T3; and extension into adjacent organs, T4 [9]

weighted imaging. Assessment of diagnostic performance of T2WI and DWI in diagnosis non-invasive and invasive urinary bladder masses were shown in Tables 4 and 5 and Figs. 2, 3, 4, and 5, considering the pathological findings as the gold standard in our study. The Kappa agreement was done for both T2WI and DWI; it revealed that the agreement was better in DWI than T2WI (Kappa was 0.756 and 0.484 ). The overall agreement of DWI, T2WI, and both were $83.6 \%, 63.6 \%$, and $65.5 \%$ respectively (Tables 6 and 7). The accuracy of DWI in diagnosis of different $\mathrm{T}$ stages were $80 \%, 43 \%, 96 \%$, and $100 \%$ while in T2WI were $55 \%, 43 \%, 74 \%$, and $80 \%$ for $\mathrm{T} 1, \mathrm{~T} 2, \mathrm{~T} 3$, and $\mathrm{T} 4$

Table 3 Illustrates the T stages for urinary bladder carcinoma based of pathological findings $[14,15]$

\begin{tabular}{|c|c|}
\hline $\begin{array}{l}\mathrm{T} \\
\text { stages }\end{array}$ & Description \\
\hline $\mathrm{Ta}$ & $\begin{array}{l}\text { The cancer is a non-invasive papillary carcinoma (Ta). It has } \\
\text { grown toward the hollow centre of the bladder but has not } \\
\text { grown into the connective tissue or muscle of the bladder wall. }\end{array}$ \\
\hline
\end{tabular}

Tis The cancer is a flat, non-invasive carcinoma (Tis), also known as flat carcinoma in situ (CIS).

T1 The cancer has grown into the layer of connective tissue under the lining layer of the bladder but has not reached the layer of muscle in the bladder wall.

T2 The cancer has grown into the inner (T2a) or outer (T2b) muscle layer of the bladder wall, but it has not passed completely through the muscle to reach the layer of fatty tissue that surrounds the bladder.

T3 The cancer has grown through the muscle layer of the bladder and into the layer of fatty tissue that surrounds the bladder.

T4 The cancer has spread into the prostate, uterus, vagina, the pelvic, or abdominal wall. respectively. The accuracy of both T2WI and DWI in T staging was $55 \%, 43 \%, 78 \%$, and $80 \%$ respectively. So, DWI showed higher accuracy than T2WI.

The ADC values were calculated for each grade of tumor. Mean \pm SD ADC value among grade 1 , grade 2, and grade 3 were $1.76 \times 10^{-3} \pm 0.16 \times 10^{-3}, 1.33 \times 10^{-3} \pm$ $0.22 \times 10^{-3}$, and $1.03 \times 10^{-3} \pm 0.171 \times 10^{-3}$, respectively. ANOVA test was done to detect the statistical difference between mean ADC value of different tumor grades (ADC value was normally distributed), it illustrated that there was a statistically significant difference between the three groups ( $P$ value $<0.0001$ and $F$ was 66.9 at 2 degree of freedom). Post hoc test was done to detect the multiple comparisons between groups (Table 8).

ROC curve was done to detect the prediction value of $\mathrm{ADC}$ in detection of stage $<\mathrm{T} 1$ (noninvasive) urinary bladder carcinoma (Fig. 6). ADC value was able to differentiate non-invasive $(<\mathrm{T} 1)$ from invasive urinary

Table 4 Diagnostic performance of T2WI in assessment of degree of muscle invasion of urinary bladder carcinoma

\begin{tabular}{lll}
\hline T2Wl findings & \multicolumn{2}{l}{ Final diagnosis } \\
\cline { 2 - 3 } & Non-invasive $\boldsymbol{n}=20$ & Invasive $\boldsymbol{n}=35$ \\
\hline Non-invasive & $11(\mathrm{TN})$ & 0 (FN) \\
Invasive & $9(\mathrm{FP})$ & $35(\mathrm{TP})$ \\
Sensitivity & $100 \%$ & \\
Specificity & $55 \%$ & \\
PPV & $80 \%$ & \\
NPV & $100 \%$ & \\
Accuracy & $84 \%$ & \\
\hline
\end{tabular}


Table 5 Diagnostic performance of DWI in assessment of degree of muscle invasion of urinary bladder carcinoma

\begin{tabular}{lll}
\hline DWls findings & \multicolumn{2}{l}{ Final diagnosis } \\
\cline { 2 - 3 } & Non-invasive $\boldsymbol{n}=20$ & Invasive $\boldsymbol{n}=35$ \\
\hline Non-invasive & $16(\mathrm{TN})$ & 0 (FN) \\
Invasive & $4(\mathrm{FP})$ & $35(\mathrm{TP})$ \\
Sensitivity & $100 \%$ & \\
Specificity & $80 \%$ & \\
PPV & $90 \%$ & \\
NPV & $100 \%$ & \\
Accuracy & $93 \%$ & \\
\hline
\end{tabular}

bladder carcinoma (> T2) $(P<0.001)$. This analysis showed that at a cutoff value of $1.225 \times 10^{-3} \mathrm{~mm}^{2} / \mathrm{s}$, ADC value had a sensitivity of $90 \%$ and a specificity of $82.9 \%$ for early detection of invasive urinary bladder carcinoma.

\section{Discussion}

Accurate preoperative staging of urinary bladder carcinoma is the most important factor for the appropriate management and better prognosis as it depends on the clinical findings and stage at presentation [16-18]. Superficial tumors are treated with transurethral resection (TUR) with or without adjuvant intravesical chemotherapy or photodynamic therapy [19], whereas invasive tumors are treated with radical cystectomy, radiation therapy, chemotherapy, or a combination [18].

Cystoscopy and biopsy are considered as invasive techniques. Hence, the purpose of this study was to assess the degree of muscle invasion of the urinary bladder carcinoma by diffusion-weighted magnetic resonance imaging (DW-MRI) as well as to measure the correlation between ADC value and histologic grade of the urinary bladder cancer.

Several studies were done to assess value of DWI as being non-invasive imaging method in differentiating stage, grade, and cell type of the urinary bladder cancer $[8,13]$. The feasibility of using DW-MR imaging for the detection of urinary bladder carcinoma has been reported by Matsuki et al. [20]. They found that the sensitivity and positive predictive value of DW imaging were both $100 \%$ for detection of carcinoma. Similar findings were reported by El-Assmy et al. [21]; the sensitivity and positive predictive values of DW-MRI were $100 \%$ in terms of correctly detecting the bladder carcinomas on 43 patients.

In a study carried out by Abou-El-Ghar et al. [11], on 130 patients with hematuria, cystoscopy was considered as a standard reference. The sensitivity, specificity, positive predictive value, negative predictive value, and
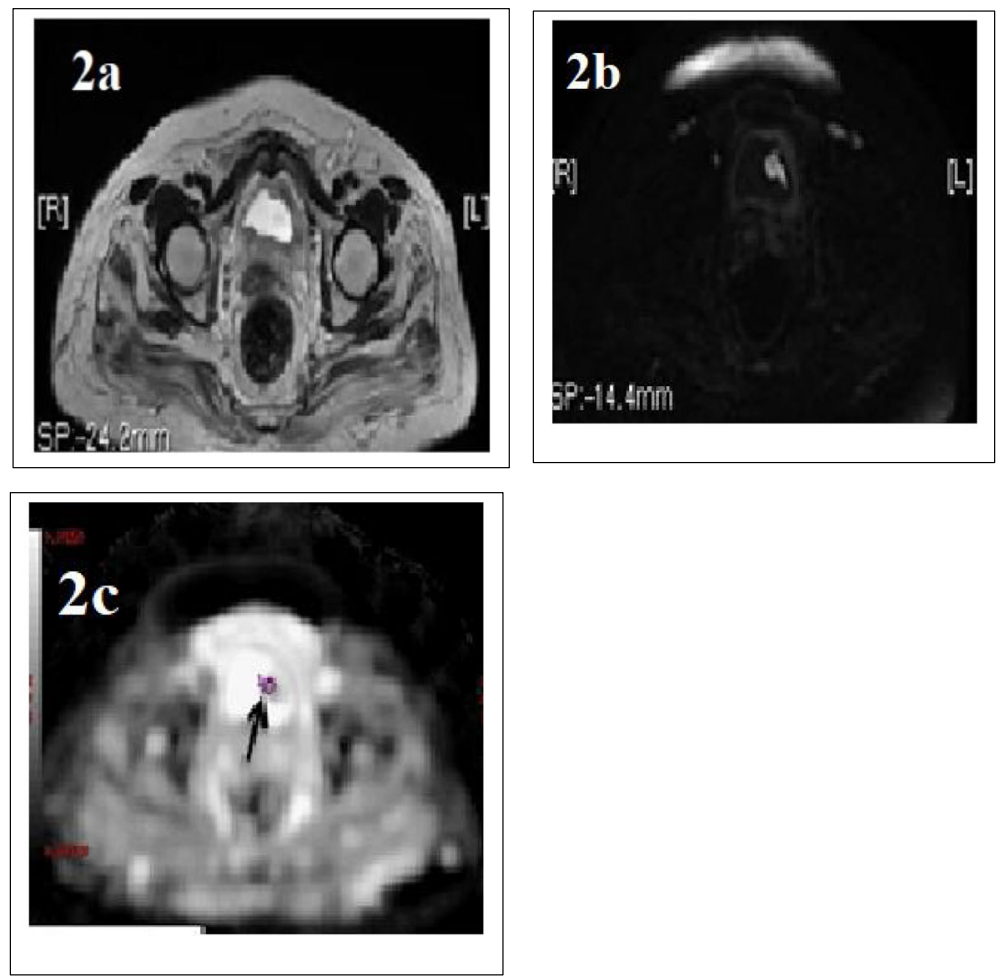

Fig. 2 Non-invasive papillary urothelial "transitional" cell carcinoma with free lamina propria and muscle layer, (stage T1, grade 1). a T2WI showing small sized mass lesion at the left anterolateral aspect of the urinary bladder wall with focal mural disruption (stage T2). $\mathbf{b}$ DWIs showing restricted diffusion of the lesion with no disruption (stage T1), matching with the pathological findings. $\mathbf{c}$ The mean $\mathrm{ADC}$ value $=1.87 \times 10^{-3} \mathrm{~mm} / \mathrm{s}$ 

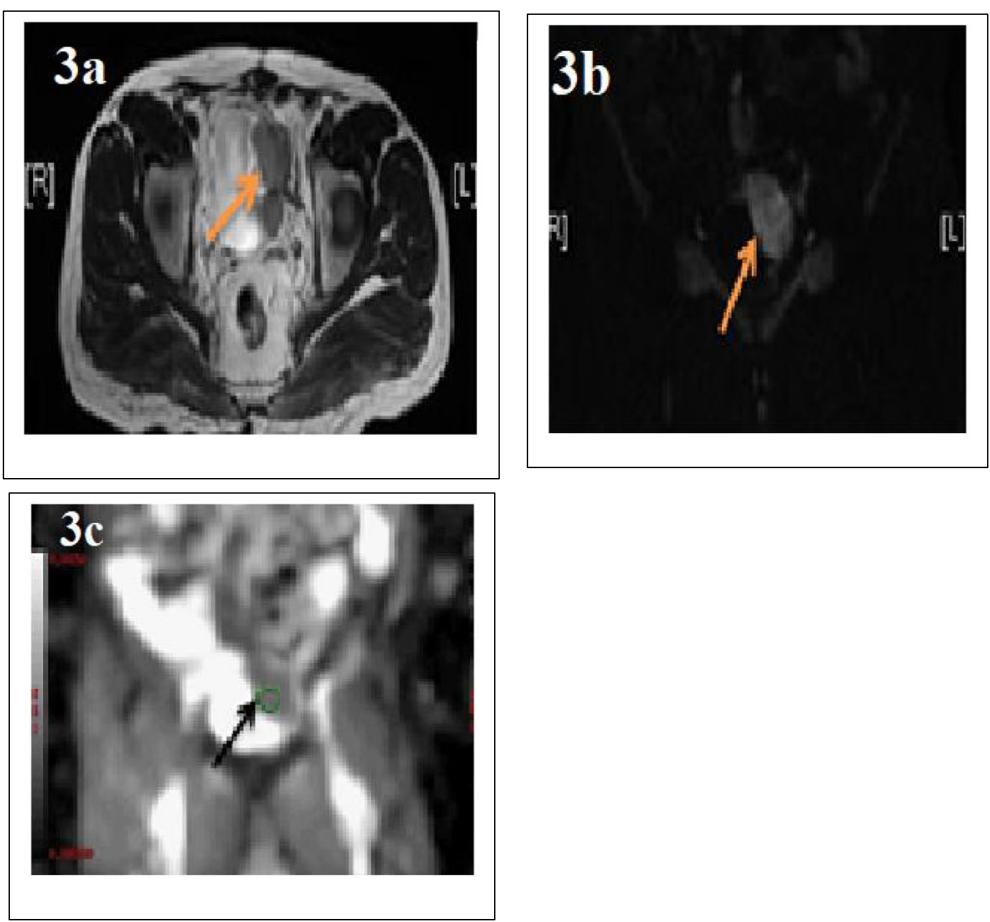

Fig. 3 Squamous cell carcinoma with extensively infiltrating the lamina propria and preserved muscle layer (stage T2, grade2). a T2WI showing soft tissue mass lesion at the left lateral wall of the urinary bladder, stage T2. b DWIs, the soft tissue mass lesion showing evidence of restricted diffusion, stageT2. c The mean ADC value measures $1.46 \times 10^{-3} \mathrm{~mm}^{2} / \mathrm{s}$

accuracy of DW-MRI regarding the degree of muscle invasion of urinary bladder carcinoma were $98.5 \%, 93.3 \%$, $100 \%, 92.3 \%$, and $97 \%$ respectively. They found excellent agreement between the DW-MR imaging and the conventional cystoscopy. These results are similar to the present study, in which the sensitivity, specificity, positive predictive value, negative predictive value, and accuracy of DW-MRI were $100 \%, 80 \%, 90 \%, 100 \%$, and $93 \%$. The results of our study and previously published studies suggest a high reliability of DW-MR imaging for the diagnosis and proper staging of bladder carcinoma. In addition, DW-MR images can provide information regarding lesion size, number, and location to surgeons who perform conventional cystoscopy.
In a study done by Takeuchi et al. [13], they also found that the sensitivity, specificity, and accuracy for differentiating non-invasive from invasive urinary bladder tumors using T2WI images alone, and combined use of T2WI and DW images were $88 \%, 74 \%, 79 \%$, and $88 \%$, $100 \%, 96 \%$ respectively.

In a study done by Rima et al. [22], they reported that adding DWI to T2WI revealed higher accuracy (83\%) than T2WI alone (75\%). This agreed with our results and other researches [13, 23-25]. In the current study, we found that the overall agreement of DWI, T2WI, and both were $83.6 \%, 63.6 \%$, and $65.5 \%$ respectively. In a study done by Abdel-Rahman et al. [26], they reported higher overall accuracy of diffusion-weighted images
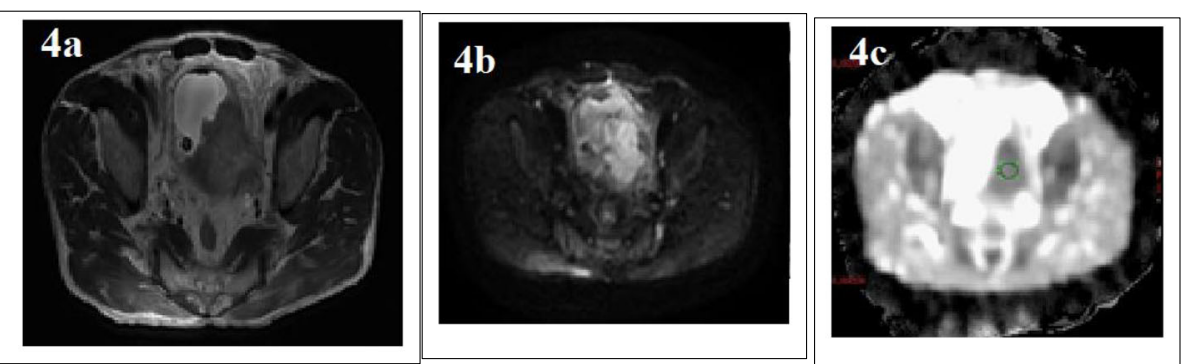

Fig. 4 Transitional cell carcinoma, stage T4 and grade 3, matching with T2WI (a) and DWI (b). The mean ADC $=1.32 \times 10^{-3} \mathrm{~mm}^{2} / \mathrm{s}$ 

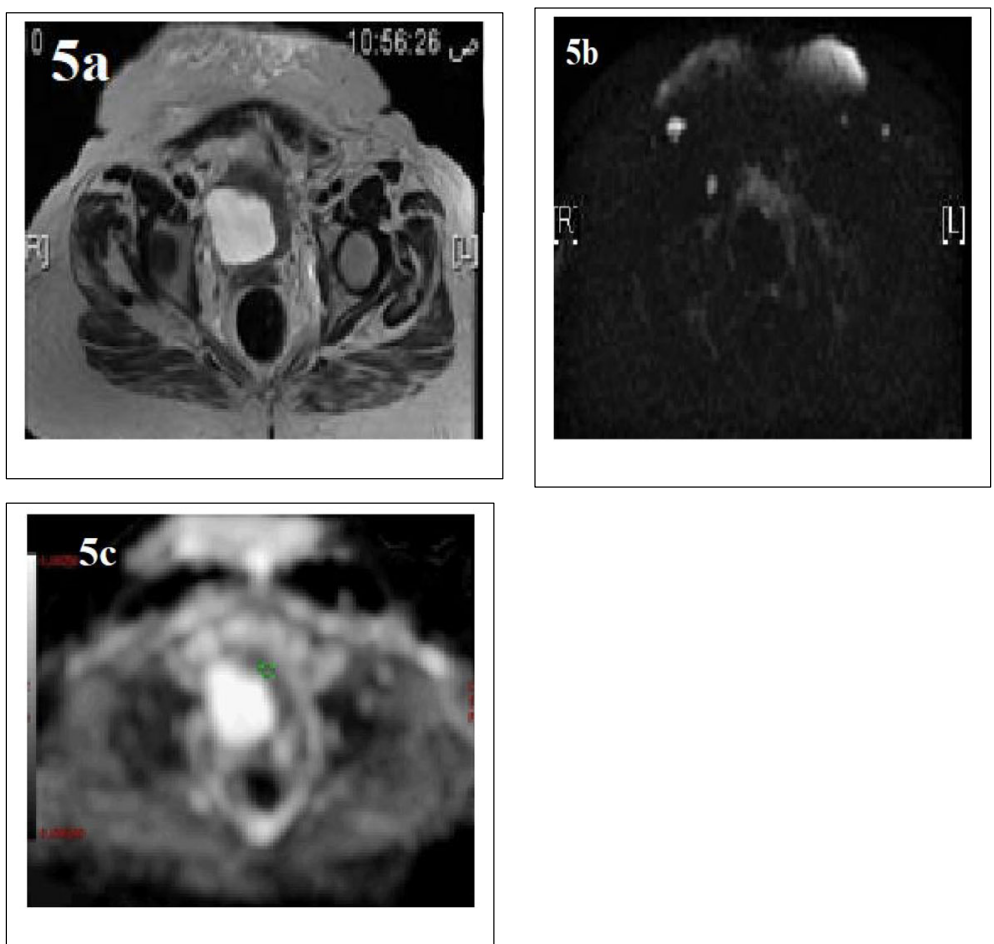

Fig. 5 Infiltrating papillary urothelial "transitional" cell carcinoma, stage T3 and grade 3, matching with T2WI (a) and DWI (b). The ADC value is towards the high-grade malignancy $(\mathbf{c})$. The mean $A D C=1.13 \times 10^{-3} \mathrm{~mm}^{2} / \mathrm{s}$

compared to T2WI in $\mathrm{T}$ staging of urinary bladder carcinoma.

Tekes et al. reported over staging of about $81 \%$ of bladder tumors when they assess the lesions using T2weighted images alone, as tumors showed signal intensity like that of muscle layer on T2-weighted images. Also, the insufficient contrast between tumor and submucosa might cause low accuracy in T2WI [27].

Several authors had reported decreased ADC value among malignant lesions due to dense cellularity and large cellular size [28]. El-Assmy et al. 2008 and Ceylan et al. 2010 found that the mean ADC values of patients who were diagnosed with a bladder tumor $\left(1.05 \pm 0.22 \times 10^{-3} \mathrm{~mm}^{2} / \mathrm{s}\right)$ were significantly lower than the mean $\mathrm{ADC}$ values obtained from the normal

Table 6 Agreement between T2WI and histopathological examination

\begin{tabular}{llllll}
\hline Pathology, T2WI & $\mathrm{T} 1$ & $\mathrm{~T} 2$ & $\mathrm{~T} 3$ & $\mathrm{~T} 4$ & Total \\
\hline T1 & $11(55)$ & $0(0)$ & $0(0)$ & $0(0)$ & $11(20)$ \\
T2 & $7(35)$ & $3(42.9)$ & $1(4.3)$ & $0(0)$ & $11(20)$ \\
T3 & $2(10)$ & $4(57.1)$ & $17(73.9)$ & $1(20)$ & $24(43.6)$ \\
T4 & $0(0)$ & $0(0)$ & $5(21.7)$ & $4(80)$ & $9(16.4)$ \\
Total & $20(100)$ & $7(100)$ & $23(100)$ & $5(100)$ & $55(100)$ \\
Kappa agreement & 0.484 & & & & \\
\hline
\end{tabular}

Data was presented as number and percent bladder wall $\left.\left(1.830 \pm 0.18 \times 10^{-3} \mathrm{~mm}^{2} / \mathrm{s}\right)[21,29]\right)$. In this study, the mean ADC of G1 tumors was significantly higher than that of G2 and G3 tumors. Meanwhile, there was an inverse relationship between the mean ADC values and the histological grade of the tumor. This was in accordance to results of different studies [20, 30, 31]. Based on our study and prior studies, the ADC values could predict the histologic grade of bladder cancer.

MRI examination including functional sequences proved to be valuable imaging modality in providing adequate information regarding morphological data and tumor cellularity [32]. Multiparametric MRI imaging (mpMRI) is considered a promising imaging modality for assessment of tumor response to

Table 7 Agreement between DWI and histopathological examination

\begin{tabular}{llllll}
\hline Pathology, DWI & T1 & T2 & T3 & T4 & Total \\
\hline T1 & $16(80)$ & $0(0)$ & $0(0)$ & $0(0)$ & $16(29.1)$ \\
T2 & $4(20)$ & $3(42.9)$ & $0(0)$ & $0(0)$ & $7(12.7)$ \\
T3 & $0(0)$ & $4(57.1)$ & $22(95.7)$ & $0(0)$ & $26(47.3)$ \\
T4 & $0(0)$ & $0(0)$ & $1(4.3)$ & $5(100)$ & $6(10.9)$ \\
Total & $20(100)$ & $7(100)$ & $23(100)$ & $5(100)$ & $55(100)$ \\
Kappa agreement & 0.756 & & & & \\
\hline
\end{tabular}

Data was presented as number and percent 
Table 8 Multiple comparisons between mean ADC value of different tumor grades

\begin{tabular}{|c|c|c|c|c|c|c|}
\hline \multirow{2}{*}{$\begin{array}{l}\text { (I) } \\
\text { Tumor } \\
\text { grading }\end{array}$} & \multirow{2}{*}{$\begin{array}{l}(\mathrm{J}) \\
\text { Tumor } \\
\text { grading }\end{array}$} & \multirow{2}{*}{$\begin{array}{l}\text { Mean } \\
\text { difference } \\
(I-J)\end{array}$} & \multirow{2}{*}{$\begin{array}{l}\text { Std. } \\
\text { error }\end{array}$} & \multirow[t]{2}{*}{$P$ value } & \multicolumn{2}{|c|}{ 95\% confidence interval } \\
\hline & & & & & Lower bound & Upper bound \\
\hline \multirow[t]{2}{*}{ Grade 1} & Grade 2 & $0.000428^{*}$ & 0.000072 & $<0.001 *$ & 0.000253 & 0.000602 \\
\hline & Grade 3 & $0.000724^{*}$ & 0.000063 & $<0.001 *$ & 0.000572 & 0.000876 \\
\hline Grade 2 & Grade 3 & $0.000296^{*}$ & 0.000059 & $<0.001 *$ & 0.000152 & 0.000441 \\
\hline Grade 3 & Grade 2 & $-0.000296^{*}$ & 0.000059 & $<0.001 *$ & -0.000441 & -0.000152 \\
\hline
\end{tabular}

"The mean difference is significant at $P$ value $<0.001$

Data presented as mean and standard error

chemotherapy and radiotherapy [32]. Multiparametric MRI imaging (mpMRI) included T2WIs, DWI, and dynamic contrast enhanced study. T1WIs are also needed to assess the presence of hemorrhage in the bladder and marrow signal alteration of the pelvic bones [33]. Vesical Imaging-Reporting and Data System (VI-RADS) is a scoring system that aims to provide guidelines for detection of urinary bladder carcinoma and the degree of muscle invasion based on findings of multiparametric MRI imaging (mpMRI) [32].

In the present study, we found that DW-MRI has many advantages such as short acquisition time, noninvasive technique, and does not contain ionized radiation. Also, DW-MR imaging can be added to routine imaging protocols particularly in patients with renal impairment who cannot be examined using contrast study. DWI was performed without breath holding, thus allowing examination of severely ill, old, or obese patients who were unable to hold their breath for a long time.

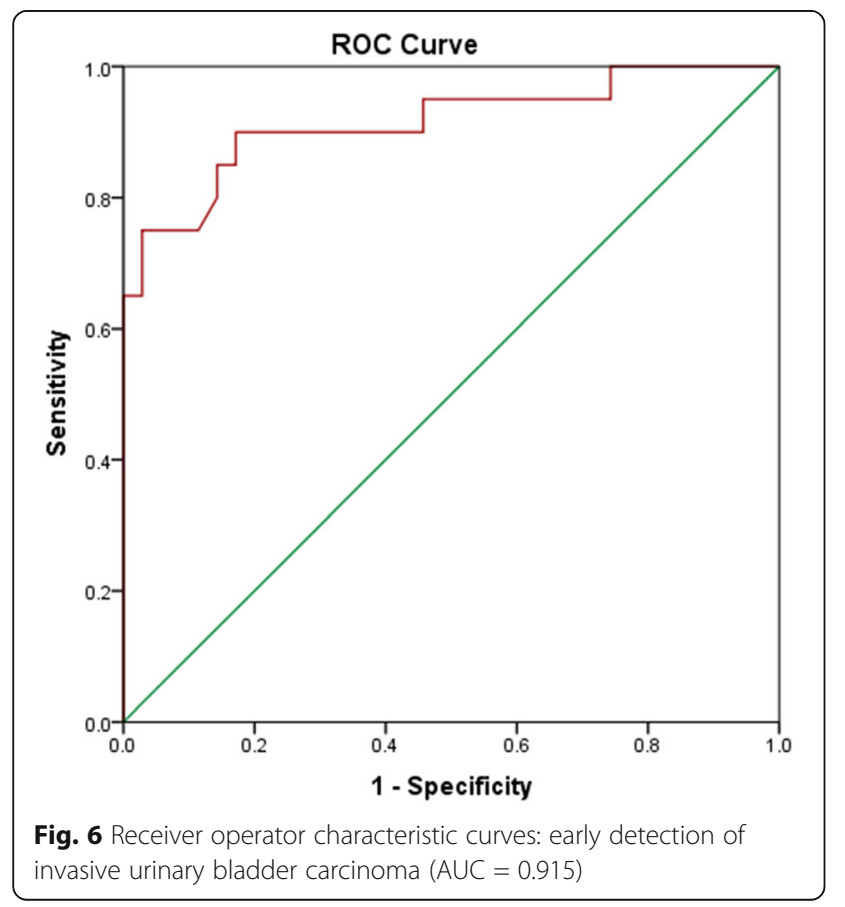

DW-MRI is a promising imaging tool. It could be accepted as an important marker of tumor cellularity.

Our study has few limitations; first, we included a larger number of advanced stage tumors. Second, images interpretation was done by one radiologist so interobserver correlation could not be assessed. Also, we did not use contrast in our study as we focused on the accuracy of diffusion imaging, to add DWI as a routine sequence in cases with urinary bladder lesions particularly in patients with impaired renal function.

\section{Conclusion}

The use of DW-MRI is a safe and non-invasive method in early detection and $\mathrm{T}$ staging of urinary bladder carcinoma. DWI showed higher accuracy than T2WI in detection of the degree of muscle invasion. In addition, the ADC value can predict the histological grade of the tumor. However, until now, we cannot sharply differentiate between different histologic grades using DWI.

\section{Abbreviations}

DWl: Diffusion-weighted images; ADC: Apparent diffusion coefficient;

MIBCs: Muscle invasive bladder carcinoma; NMIBCs: Non-muscle invasive bladder carcinoma; TUR: Transurethral resection; ROC: Receiver operating characteristic; mpMRI: Multiparametric MRI imaging

\section{Acknowledgements}

Not applicable.

\section{Authors' contributions}

S.A carried out the statistical analysis, data collection, image analysis, drafting, and editing of the paper. AM carried out the clinical assessment. Contributing authors have read and approved the manuscript.

Funding

No funding resources.

Availability of data and materials

All data are available at the corresponding author who has the authority to respond if there is any query.

Ethics approval and consent to participate

The study was approved from the ethical committee of Faculty of Medicine Beni-suef University (FWA00015574). Data were collected after obtaining informed written consent of all cases.

Consent for publication

All patients included in this research gave written informed consent to publish the data contained within this study. 


\section{Competing interests}

The authors declare that they have no competing interests.

\section{Author details}

${ }^{1}$ Faculty of Medicine, Beni-suef University, Beni-suef, Egypt. ${ }^{2}$ Faculty of Medicine, Beni-suef University, Beni-suef, Egypt.

Received: 10 February 2020 Accepted: 17 March 2020

Published online: 27 March 2020

\section{References}

1. Wong-You-Cheong JJ, Woodward PJ et al (2006) Neoplasms of the urinary bladder: radiologic-pathologic correlation. RadioGraphics 26:553-580

2. Verma S, Rajesh A, Prasad SR et al (2012) Urinary bladder cancer: role of MR imaging. RadioGraphics 32:371-387

3. Ferlay J, Shin HR, Bray F, Forman D, Mathers CD, Parkin D. GLOBOCAN 2008, Cancer incidence and mortality worldwide: IARC CancerBase No. 10. Lyon: International Agency for Research on Cancer; Available at: http://globocan. iarc.fr. 2010. Last accessed 8/17/2010.

4. Sliverman D, Devesa S, Moore L, Rothman N (2006) Bladder cancer. In: Schottenfeld D, Fraumeni FJ Jr (eds) Cancer Epidemiology and Prevention, 3rd edn. Oxford University Press, Oxford, pp 1101-1027

5. Felix AS, Soliman AS, Khaled $\mathrm{H}$ et al (2008) The changing patterns of bladder cancer in Egypt over the past 26 years. Cancer Causes Control 19: 421-429

6. Zaghloul MS, Nouh A, Moneer M, El-Baradie M, Nazmy M, Younis A (2008) Time-trend in epidemiological and pathological features of schistosomaassociated bladder cancer. J Egypt Natl Canc Inst 20:168-174

7. Kaufman DS, Shipley WU, Feldman AS (2009) Bladder cancer. Lancet 374 239-249

8. Lee M, Shin SJ, Oh YT et al (2017) Non-contrast magnetic resonance imaging for bladder cancer: fused high b value diffusionweighted imaging and T2-weighted imaging helps evaluate depth of invasion. Eur Radiol. 27: 3752-3758

9. Walsh PC, Retik AB, Stamey TA (2007) Urothelial tumors of the bladder. Campbell Walsh Urology, 9th edn. Sauders, Philadephia, p 2439

10. Kobayashi S, Koga F, Yoshida S (2011) Diagnostic performance of diffusionweighted magnetic resonance imaging in bladder cancer: potential utility of apparent diffusion coefficient values as a biomarker to predict clinical aggressiveness. Eur Radiol. 21:2178-2186

11. Abou-El-Ghar ME, El-Assmy A, Refaie HF, El-Diasty T (2009) Bladder cancer: diagnosis with diffusion weighted MR imaging in patients with gross hematuria. Radiology. 251:415-421

12. Thoeny HC, De Keyzer F (2007) Extracranial applications of diffusionweighted magnetic resonance imaging. Eur Radiol 17(6):1385-1393

13. Takeuchi M, Sasaki S, Ito M et al (2009) Urinary bladder cancer: diffusionweighted MR imaging-accuracy for diagnosing $T$ stage and estimating histologic grade. Radiology 251(1):112-121

14. American Cancer Society (2017) Cancer Facts \& Figures 2017. American Cancer Society, Atlanta

15. American Joint Committee on Cancer (2010) AJCC Cancer Staging Manual. Urinary Bladder, 7th edn. Springer, New York, pp 497-502

16. McLaughlin S, Shephard J, Wallen E et al (2007) Comparison of the clinical and pathologic staging in patients undergoing radical cystectomy for bladder cancer. Int Braz J Urol 33:25-32

17. Sobin LH, Gospodariwicz MK, Wittekind C (2009) International Union against Cancer. TNM classification of malignant tumours, 7th edn. Wiley-Blackwell, Oxford

18. Sherif A, Jonsson MN, Wiklund NP (2007) Treatment of muscle-invasive bladder cancer. Expert Rev Anticancer Ther. 7:1279-1283

19. Josephson D, Pasin E, Stein JP (2007) Superficial bladder cancer. II. Management. Expert Rev Anticancer Ther 7:567-581

20. Matsuki M, Inada Y, Tatsugami F et al (2007) Diffusion-weighted MR imaging for urinary bladder carcinoma: initial results. Eur Radiol 17(1):201-204

21. El-Assmy A, Abou-El-Ghar ME, Refaie HF, El-Diasty T (2008) Diffusionweighted MR imaging in diagnosis of superficial and invasive urinary bladder carcinoma: a preliminary prospective study. Sci World J 8:364-370

22. Al Johi RS, Seifeldein GS, Moeen AM et al (2018) Diffusion weighted magnetic resonance imaging in bladder cancer, is it time to replace biopsy? Cent European J Urol. 71:31-37
23. Watanabe $\mathrm{H}$, Kanematsu M, Kondo $\mathrm{H}$ et al (2009) Preoperative $\mathrm{T}$ staging of urinary bladder cancer: does diffusion-weighted MRI have supplementary value? AJR. 192:1361-1366

24. Yamada Y, Kobayashi S, Isoshima S, Arima K, Sakuma H, Sugimura Y (2014) The usefulness of diffusion weighted magnetic resonance imaging in bladder cancer staging and functional analysis. J Cancer Res Ther. 10:878-882

25. Gupta N, Sureka B, Kumar MM, Malik A, Bhushan TB, Mohanty NK (2015) Comparison of dynamic contrast-enhanced and diffusion weighted magnetic resonance image in staging and grading of carcinoma bladder with histopathological correlation. Urol Ann. 7:199-204

26. Abdel-Rahman HM, El Fiki IM, Desoky EAE, Elsayed ER, Abd Samad KM (2015) The role of diffusion-weighted magnetic resonance imaging in T staging and grading of urinary bladder cancer. Egypt J Radiol Nucl Med. 46: 741-747

27. Tekes A, Kamel I, Imam K et al (2005) Dynamic MRI of bladder cancer: evaluation of staging accuracy. AJR Am J Roentgenol 184:121-127

28. Woodhams R, Matsunaga K, Kan S et al (2005) ADC mapping of benign and malignant breast tumors. Magn Reson Med Sci 4:35-42

29. Ceylan K, Taken K, Gecit I et al (2010) Comparison of cystoscopy with diffusion-weighted magnetic resonance images used in the diagnosis and follow-up of patients with bladder tumors. Asian Pac J Cancer Prev 11: 1001-1004

30. Wang H, Guan J, Guo Y, Guang Z (2014) Estimation of bladder carcinoma histologic grade with diffusion weighted MR imaging. Eur Soc Radiol. 138: 409-414

31. Sherif MF (2015) The value of diffusion weighted MR imaging in T staging and correlation with histologic grading in urinary bladder cancer. Egypt J Radiol Nucl Med. 46:189-194

32. Thoeny HC, Bellin MF, Comperat EM, Thalmann GN (2018) Vesical ImagingReporting and Data System (VI-RADS): added value for management of bladder cancer patients? Eur Urol https://doi.org/10.1016/j.eururo.2018.06.017

33. Panebianco V, Narumi Y, Altun E, Bochner B, Efstathiou J et al (2018) Multiparametric magnetic resonance imaging for bladder cancer: development of VI-RADS (Vesical Imaging-Reporting And Data System). Eur Urol https://doi.org/10.1016/j.eururo.2018.04.029

\section{Publisher's Note}

Springer Nature remains neutral with regard to jurisdictional claims in published maps and institutional affiliations.

\section{Submit your manuscript to a SpringerOpen ${ }^{\circ}$ journal and benefit from:}

- Convenient online submission

- Rigorous peer review

- Open access: articles freely available online

High visibility within the field

- Retaining the copyright to your article

Submit your next manuscript at $>$ springeropen.com 